\title{
RANCANG BANGUN DAN UJI KINERJA PENERAPAN TEKNIK IRIGASI TETES PADA LAHAN KERING
}

\author{
Muanah $^{1 *}$, Karyanik', Erni Romansyah' \\ ${ }^{1}$ Program Studi Teknik Pertanian, Universitas Muhammadiyah Mataram, Indonesia \\ co-author: muanahtp@gmail.com
}

Paper Information
History:
Received : 29-08- 2020
Accepted: $30-10-2020$

\section{Keywords:}

Drip irrigation

The droplet discharge

The uniformity of drops

Dry land

\section{A. LATAR BELAKANG}

Lahan kering di Nusa Tenggara Barat mencapai 1.807.463 ha dari total luas wilayah $20.153,15 \mathrm{~km}^{2}$. Berdasarkan luasan ini menurut (Mulyani and Las, 2008) bahwa lahan kering ini dominan berada di Kabupaten Lombok Timur bagian selatan salah satunya di Kecamatan Keruak Desa Batu Putik.

Lahan kering selain jumlahnya lebih dominan juga memiliki produktifitas yang rendah (Sarwani,

\section{ABSTRACT}

Abstrak: Tujuan penelitian ini adalah merancang dan melakukan uji kinerja teknik irigasi tetes pada lahan kering. Metode penelitian ini menggunakan rancangan acak lengkap dengan 3 perlakuan yaitu kemiringan keran $15^{\circ}, 45^{\circ}$, dan $90^{\circ}$ dengan 4 kali ulangan. Sehingga diperoleh 12 unit sampel percobaan. Selanjutnya hasil perancangan dilakukan pengujian debit tetesan, koefisien keseragaman, luasan tanah terbasahi, serta jumlah kebutuhan air selama pertumbuhan vegetatif tanaman tomat. Hasil pengujian berdasarkan nilai debit dan keseragaman tetes menunjukkan bahwa perancangan teknik irigasi tetes sudah sangat baik untuk diterapkan pada lahan kering. Berdasarkan nilai debit diperoleh areal terbasahi dengan lebar pembasahan $25 \mathrm{~cm}$ dan kedalaman mencapai $35 \mathrm{~cm}$. Sehingga selama pertumbuhan vegetatif tanaman tomat pada perlakuan $15^{0}$ membutuhkan air sebanyak 10200 ml/hari, 12200 $\mathrm{ml} /$ hari pada perlakuan 450, dan $30800 \mathrm{ml} /$ hari pada perlakuan 90 . Melihat pengaruhnya terhadap pertumbuhan tanaman tomat maka dapat disimpulkan bahwa $15^{\circ}$ merupakan perlakuan terbaik untuk diterapkan pada lahan kering.

\begin{abstract}
The purpose of this study was to design and test the performance of drip irrigation techniques on dry land. This research method used a completely randomized design with 3 treatments, namely the faucet slope of $15^{\circ}, 45^{\circ}$, and $90^{\circ}$ with 4 replications. In order to obtain 12 experimental sample units. Furthermore, the design results were carried out by testing the droplet discharge, uniformity coefficient, wetted soil area, and the amount of water needed during the vegetative growth of tomato plants. The test results based on the discharge value and the uniformity of drops show that the drip irrigation technique design is very good for application on dry land. Based on the discharge value, the wetted area is obtained with a wetting width of $25 \mathrm{~cm}$ and a depth of up to $35 \mathrm{~cm}$. So that during the vegetative growth of tomato plants in treatment 150 requires $10200 \mathrm{ml} /$ day of water, $12200 \mathrm{ml} /$ day in treatment $45^{\circ}$, and $30800 \mathrm{ml} /$ day in treatment $90^{\circ}$. Seeing the effect on tomato plant growth, it can be concluded that $15^{\circ}$ is the best treatment to apply on dry land.
\end{abstract}

2013). Hal ini terjadi karena lahan kering memiliki curah hujan yang rendah, sedangkan air hujan merupakan satu-satunya sumber irigasi masyarakat. Maka dari itu siklus tanam masyarakat selama ini sebanyak dua kali musim tanam selebihnya lahan dibiarkan kosong .

Berdasarkan uraian masalah di atas beberapa kajian sudah dilakukan diantaranya dengan menerapkan metode pendistribusian air secara efektif dan efisien 
diantaranya menggunakan irigasi springkel, tetesan bawah tanah dan tetesan pemukaan tanah.

. Irigasi tetes merupakan irigasi bertekanan rendah dan dapat diatur secara tepat baik volume maupun sasarannya (Ridwan, 2013). Selain itu juga penggunaan sistem irigasi tetes dapat meningkatkan produktifitas lahan dan tanaman karena lahan dapat ditanami sepanjang tahun sehingga indeks penanaman meningkat dan kegiatan budidaya tidak tergantung pada musim hujan (Amuddin and Sumarsono, 2015).

Rancangan irigasi tetes sudah banyak dikaji dan diterapkan oleh masyarakat, namun rancangan yang optimal sesuai dengan kondisi lahan kering di Desa Batu Putik Lombok Timur belum pernah dikaji sehingga perlu perancangan yang optimal untuk pertumbuhan tanaman tomat.

Berdasarkan uraian di atas tujuan dilakukan penelitian ini: (1) untuk membuat perancangan yang tepat sesuai kondisi lahan kering di Desa Batu Putik dan; (2) melakukan uji kinerja penerapan teknik irigasi tetes pada budidaya tanaman tomat.

\section{B. METODE PENELITIAN}

Kegiatan penelitian mencakup pembuatan model jaringan irigasi tetes, kemudian dilakukan uji kinerja langsung pada lahan kering di Desa Batu Putik kabupaten Lombok Timur.

Alat dan bahan rancangan irigasi tetes terdiri dari: (1) Tangki penampung air kapasitas 550 liter; (2) selang karet untuk menyalurkan air dari reservoir ke tangki penampunga; (3) selang irigasi tetes tempat lubang emitter; (4) conector irigasi tetes sebagai control debit air pada setiap perlakuan; (5) pipa PVC 3/4 inchi sebagai saluran air primer menuju aliran sekunder; (5) alat uji kinerja terdiri dari gelas ukur, stop watch, dan penggaris. Adapun bahan yang digunakan adalah air sawah tanpa dilakukan penyaringan terlebih dahulu, dan tanaman tomat.

Penelitian ini menggunakan rancangan acak lengkap (RAL) dengan 3 perlakuan 4 kali ulangan, sehingga diperoleh 12 unit percobaan. Berikut adalah masing-masing perlakuan:

$\mathbf{P 1}=$ debit dengan kemiringan keran $15^{\circ}$

P2 $=$ debit dengan kemiringan keran $45^{\circ}$

$\mathbf{P 3}=$ debit dengan kemiringan keran $90^{\circ}$

Uji teknis dilakukan secara langsung pada lahan petani dengan pengujian sebagai berikut: (1) Debit emitter; (2) koefisien keseragaman tetes; (3) kebutuhan air tanaman. Pengambilan sampel pengukuran debit air dilakukan secara acak pada 20 tanaman disetiap bedengan. Posisi tendon diletakan pada ketinggian 30 $\mathrm{cm}$ dari tempat penanaman. Pengambilan data juga dilakukan pada saat tampungan air terisi penuh (500 liter) dan setengan (250 liter ke bawah) untuk mendapatkan hasil pengukiran yang akurat. Debit dan keseragaman tetes diseting melalui conektor sambungan antara saluran primer dan skunder. Pengukuran volume pada masing-masing emiter dengan cara menampung tetesan air menggunakan gelas ukur kemudian dihitung sesuai waktu yang sudah ditentukan. Volume air setelah ditampung, lalu dibandingkan dengan jumlah waktu yang dibutuhkan sehingga diperoleh debit dalam satuan vomue per satuan waktu (liter/detik).Kebutuhan air pertanaman untuk mengetahui total penggunaan air selama pertumbuhan vegetatif. Model rancangan irigasi tetes dapat dilihat pada Gambar 1.

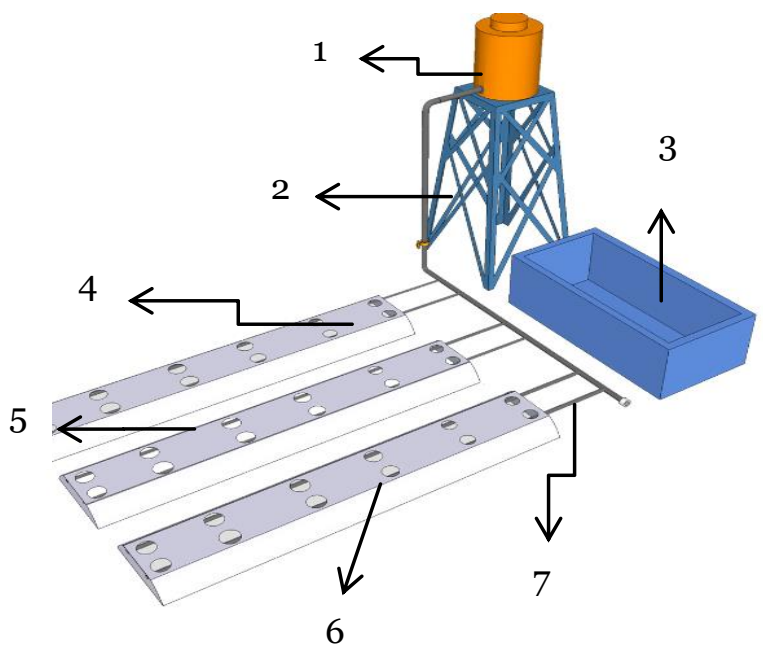

Gambar 1. Desain rancangan teknik irigasi tetes

Keterangan:

1. Tangki penampungan air

2. Tangga penampungan air

3. Reservoir air

4. Pipa utama saluran air

5. Bedengan yang tertutup dengan mulsa hitam perak

6. Lubang mulsa dan emitter

7. Selang emitter

\section{Persamaan matematika parameter pengujian:}

\section{Debit penetes emitter}

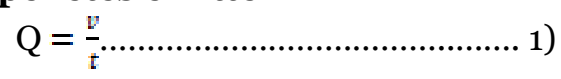

Keterangan :

$\mathrm{Q}=$ debit penates (liter/detik)

$\mathrm{V}=$ volume tetesan emitter (liter)

$\mathrm{T}=$ waktu (detik)

\section{Koefisien Keseragaman Tetes}

$$
\mathrm{Cu}=100\left(1-\frac{\left.\sum[\alpha i-\mathbb{\pi}]\right]}{\sum \alpha i}\right)
$$

Keterangan :

$\mathrm{Cu}=$ koefisien keseragaman irigasi (\%)

$\mathrm{Ai}=$ nilai masing-masing air pada wadah $(\mathrm{ml})$

$\bar{\alpha}=$ nilai rata-rata dari volume air pada wadah $(\mathrm{ml})$

$\Sigma\left[\alpha_{i}-\bar{\alpha}\right]=$ jumlah deviasi absolut rata-rata pengukuran (ml) 


\section{Menentukan kebutuhan air tanaman}

$$
\mathrm{G}=\mathrm{d} . \mathrm{Sp} . \mathrm{Sr} .
$$

Keterangan:

$\mathrm{G}=$ kebutuhan air pertanaman (liter/hari)

$\mathrm{d}=$ kedalaman irigasi bruto $(\mathrm{m})$

$\mathrm{Sp}=$ jarak antar tanaman $(\mathrm{m})$

$\mathrm{Sr}=$ jarak alur tanaman $(\mathrm{m})$

Data yang sudah didapatkan selanjutnya dianalisis menggunakan mikrosoft excel dan disajikan dalam bentuk tabel.

\section{HASIL DAN PEMBAHASAN}

\section{Rancangan Teknik Irigasi Tetes}

Irigasi tetes merupakan pengaliran air secara perlahan dalam bentuk tetesan menggunakan emitter yang terletak pada titik tumbuh tanaman sepanjang aliran air.Melalui penerapan irigasi tetes diharapkan dapat menjadi alternatif pemenuhan kebutuhansistem irigasi pada lahan kering. Maka dari itu untuk mewujudkan hal tersebut perlu perancangan yang baik dan sesuai sasaran.

Model jaringan irigasi tetes didesain berdasarkan kemudahan pengaplikasian di lapangan. Penyaluran air dari tangki penampungan menuju emitter dengan memanfaatkan ketinggian gravitasi, kecuali pada pengisian tangki penampung dari reservoir mengguanakan mesin air karena jarak antara reservoir dengan tangki penampung cukup jauh. Komponen dalam perancangan irigasi tetes yang diterapkan terdiri dari :

1. Conektor irigasi tetes (Valve offtake)

Valve offtakemerupakan konektor yang menghubungkan saluran primer (pipa utama yang terbuat dari pipa PVC 3/4 inchi dan saluran sekunder (selang emitter).Valve offtake ini juga tempat mengatur setingan tiap perlakuan pada kemiringan $15^{\circ}, 45^{\circ}$, dan $90^{\circ}$.Tujuan perlakuan dengan kemiringan tersebut untuk melihat efisiensi penggunaan air, namun dampaknya terhadap pertumbuhan tanaman masih tercukupi.Conektor irigasi yang digunakan dapat dilihat pada Gambar 2.

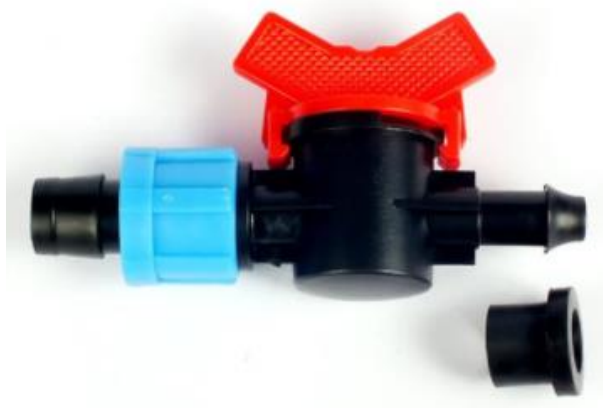

Gambar 2. Conektor irigasi tetes (valve offtake)
2. Selang irigasi (drip irrigation)

Selang irigasi ini merupakan komponen penting pada perancangan teknik irigasi tetes. Pada penelitian ini selang irigasi (drip irrigation) dilubangi pada bagian atas dengan pertimbangan untuk menghindari tertutupnya emitter. Walaupun begitu penutupan juga kadang terjadi karena air irigasi yang digunakan tanpa dilakukan penyaringan terlebih dahulu, sehingga pada saat pemberian air perlu dilakukan pengontrolan. Pengujian lubang emitter dilakukan setelah melihat secara kasar bahwa tetesan air pada emitter sudah stabil.Setelah itu baru dilakukan pengambilan data. Selang irigasi yang digunakan berukuran $4 \mathrm{~cm}$ dapat dilihat pada Gambar 3.

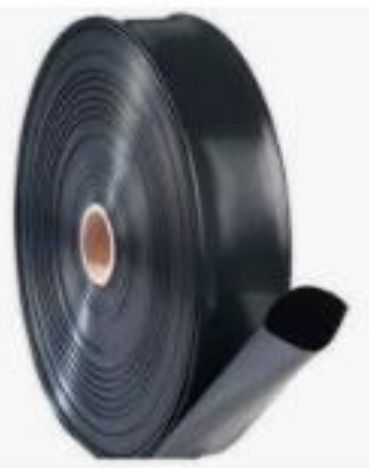

Gambar 3. Selang irigasi tetes (drip irrigaration)

3. Mulsa plastik hitam perak

Mulsa plastik hitam perak berfungsi untuk mempertahankan kelembaban tanah dan pertumbuhan gulma. Kelembaban tanah mempengaruhi tingkat pertumbuhan tanaman, hal ini juga dibuktikan oleh (Djumali and S., 2014) bahwa penurunan kelembaban tanah berbanding lurus dengan jumlah produksi yang dihasilkan. Pada penelitian yang dilakukan kelembaban udara pada $\mathrm{P}_{1}, \mathrm{P}_{2}$, dan $\mathrm{P}_{3}$ tidak berbeda nyata yaitu berkisar antara 50\%-70\% dan kisaran ini sudah memenuhi persyaratan untuk mendukung pertumbuhan tanaman tomat. Selain itu juga pada penelitian yang dilakukan oleh (Selvamurugan et al., 2018) bahwa penggunaan mulsa lebih unggul dari yang lain karena mampu memperpanjang batas kritis penurunan air serta meningkatkan efisiensi penggunaan air.

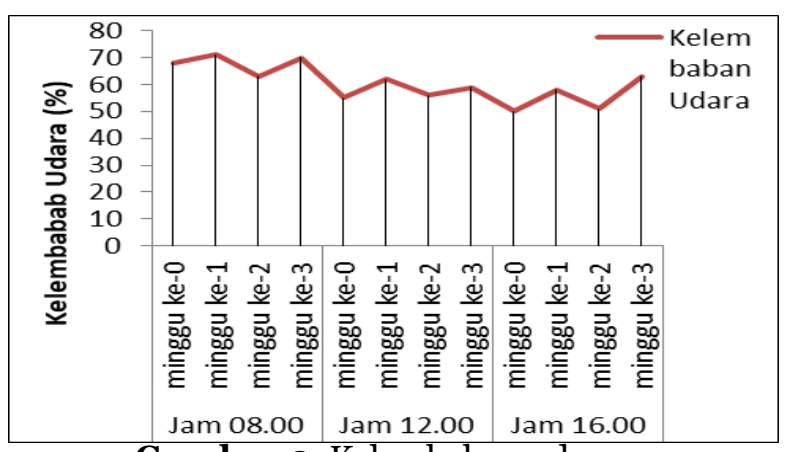

Gambar 3. Kelembaban udara 
4. Tangki penampungan air

Kapasitas penampunga air pada perancangan dan pengujian teknik irigasi tetes ini 550 liter. Pengaplikasian dengan memanfaatkan grafitasi pada jarak $10 \mathrm{~m}^{2}$ dari tangki penampung dan diletakkan pada ketinggian $30 \mathrm{~cm}$. Berikut adalah model jaringan teknik irigasi tetes terpasang dapat dilihat pada Gambar 4.

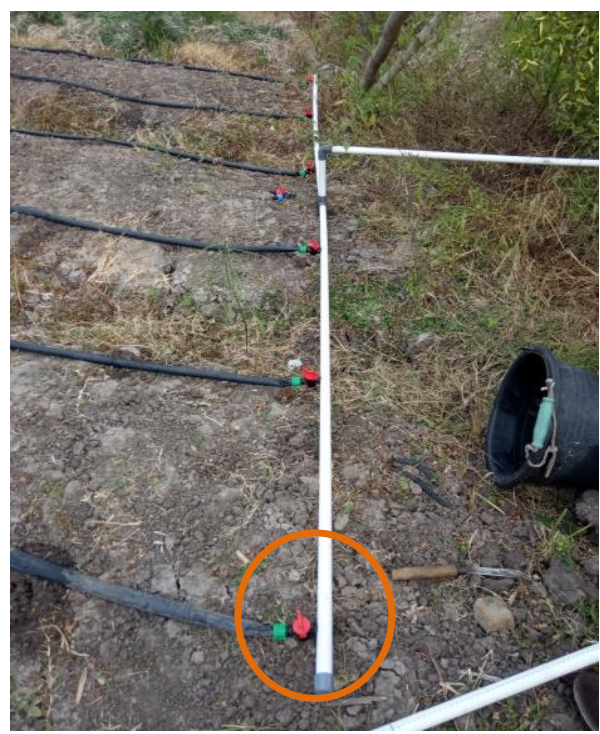

(a)

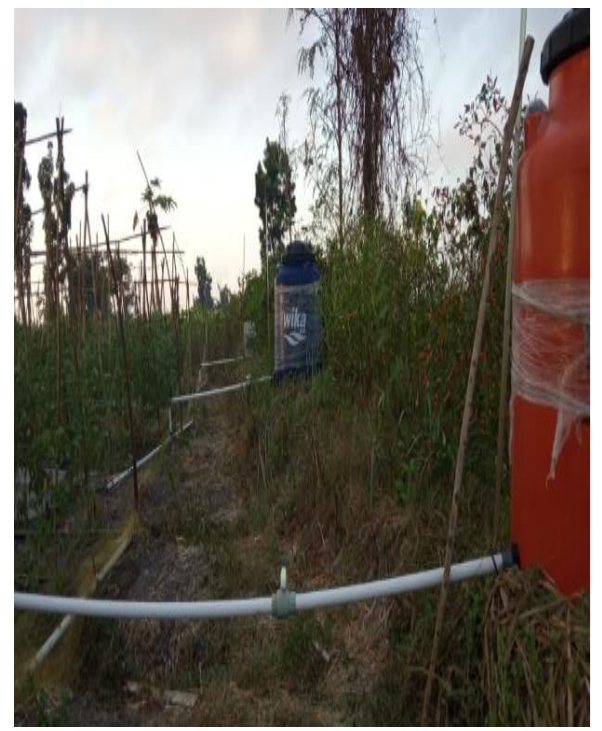

(b)

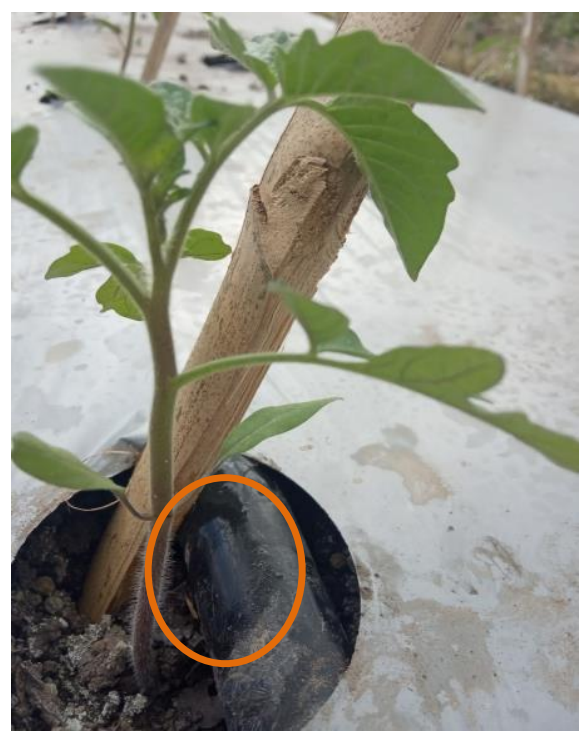

(c)

Gambar 4.(a) posisi pemasangan conektor, (b) perancangan utuh teknik irigasi tetes, (c) emitter penetes

\section{2. pengujian perancangan teknik irigasi tetes}

\section{Debit pengujian Irigasi Tetes}

Teknik irigasi tetes bertujuan untuk mengefisiensikan penggunaan air secara tepat, sehingga perlu dirancang seefektif mungkin agar mendapatkan pertumbuhan tanaman tomat yang optimal. Setelah perancangan kemudian dilakukan pengujian debit dan koefisien keseragaman tetesnya pada setiap emiter. Pengujian debit air dilakukan selama 8 menit, hal yang sama juga dilakukan pada penelitian (Rizal, 2013) bahwa emitter pada penerapan irigasi tetes perlu dilakukan pengujian minimal selama 8 menit serta pengujian dilakukan dengan memilih emiter secara acak dengan pengulangan sebayak 4 kali untuk mendapatkan pengukuran yang baik. Pengukuran debit dilakukan dengan cara menampung banyaknya air yang keluar dari emiter, kemudian dibandingkan dengan jumlah waktu yang dibutuhkan, sehingga didapatkan debit air dengan satuan liter perdetik. Berikut merupakan hasil pengujian debit air dari masing-masing perlakuan perancangan irigasi tetes pada Tabel 1.

Hasil pengujian pada masing-masing perlakuankemiringan $15^{\circ}$ berkisar antara 0,000183 liter/detik-0,000250 liter/detik, kemiringan $45^{\circ}$ memiliki debit o,000233 liter/detik-0,000267 liter/detik, dan kemiringan $90^{\circ}$ antara 0,000617 liter/detik-0,000667 liter/detik.Berdasarkan hasil analisis statistik menunjukkan bahwa pada perlakukan 1, 2, dan 3 tidak berbeda nyata dengan nilai sig kurang dari 0,005 (sig<0,005). Selain itu juga dibuktikan pada respon pertumbuhan tanaman tomat bahwa debit air pada semua perlakuan sudah dikategorikan cukup stabil.

\section{Koefisien Keseragaman Tetes}

Keseragaman sistem irigasi tetes bertujuan untuk melihat tingkat penyebaran air yang mengalir di tiaptiap emitter pada suatu sistem perancangan yang diterapkan (Ekaputra et al., 2017). Koefisien keseragaman tetes yang dihasilkan berdasarkan sajian Tabel 1 pada masing-masing perlakuan. Rata-rata nilai $\mathrm{Cu}$ terendah ditemukan pada perlakuan pertama (15) sebesar 90,23\%, sedangkan nilai tertinggi ditemukan pada perlakuan ketiga $\left(90^{\circ}\right)$ mencapai $97,40 \%$. Rincian masing-masing perlakuan dapat di lohat pada tabel 1 . Berdasarkan nilai pengujian ini bahwa perancangan teknik irigasi tetes sudah layak untuk diterapkan. Hasil ini juga didukung oleh penelitian (Franata, Oktafri and Tusi, 2014), (Fajar, Abdullah and Priyati, 2018), dan (Indarta and Tuasikal, 2020)bahwa pada pengujian irigasi sistem kontrol fertigasi rancangan sistem irigasi yang diterapkan mencapai rata-rata di atas $90 \%$. 


\section{Tabel 1}

Koefisien Keseragaman Dan Debit Irigasi Tetes

\begin{tabular}{cccccc}
\hline $\begin{array}{c}\text { Kemiringan } \\
\text { Keran (o) }\end{array}$ & Emiter & $\begin{array}{c}\text { Volume } \\
\text { (ml) }\end{array}$ & $\begin{array}{c}\text { Waktu } \\
\text { (menit) }\end{array}$ & $\begin{array}{c}\text { Debit } \\
\text { (Liter/detik) }\end{array}$ & CU(\%) \\
\hline \multirow{2}{*}{15} & 1 & 11 & 1 & 0.000183 & 84.09 \\
& 2 & 15 & 1 & 0.000250 & 85.00 \\
& 3 & 12 & 1 & 0.000200 & 93.75 \\
& 4 & 13 & 1 & 0.000217 & 98.08 \\
\hline \multirow{2}{*}{45} & 1 & 16 & 1 & 0.000267 & 95.31 \\
& 2 & 16 & 1 & 0.000267 & $95 \cdot 31$ \\
& 3 & 14 & 1 & 0.000233 & 91.07 \\
& 4 & 15 & 1 & 0.000250 & 98.33 \\
\hline \multirow{2}{*}{90} & 1 & 38 & 1 & 0.000633 & 98.68 \\
& 2 & 40 & 1 & 0.000667 & 96.25 \\
& 3 & 39 & 1 & 0.000650 & 98.72 \\
& 4 & 37 & 1 & 0.000617 & 95.95 \\
\hline
\end{tabular}

\section{Luasan Areal Terbasahi}

Debit air yang diterapkan memiliki dampak terhadap luasan areal yang terbasahi yaitu lebar dan kedalamannya. Luasan pembahasan yang dihasilkan ini harus sesuai dengan perakaran tanaman tomat yang dibudidayakan, jika tidak makaakan menghambat pertumbuhan.

Lebar dan kedalaman pembasahan diketahui dengan pengukuran langsung dan memilih secara acak 4 tanaman dan diulangi sebanyak 3 kali. Contoh areal pembasahan dapat dilihat pada Gambar 5 .

Hasil pengamatan luasan areal pembasahan untuk budidaya tanaman tomat dengan waktu operasi 30 menit menghasilkan lebar pembasahan $15 \mathrm{~cm}-18 \mathrm{~cm}$ untuk perlakuan $15^{\circ}, 15 \mathrm{~cm}-18 \mathrm{~cm}$ dan lebar tertinggi ditemukan pada debit perlakuan 90\% yaitu mencapai 20 $\mathrm{cm}-25 \mathrm{~cm}$. Begitu juga dengan kedalaman pembahasan tertinggi ditemukan pada perlakuan ketiga dengan kedalaman mencapai $35 \mathrm{~cm}$, sedangkan untuk perlakuan terendahnya ditemukan pada perlakuan pertama yaitu $15 \mathrm{~cm}$. Hasil pengamatan ini menurut (Phocaides, 2007) sudah sesuai untuk tanaman dengan akar dangkal seperti cabe, kacang tanah, jagung dan lain-lain.

Lebar dan kedalaman pembasahan menurut (Haridjaja et al., 2013) dipengaruhi oleh beberapa faktor seperti laju dan volume pemberian air serta tekstur, struktur, kemiringan dan lapisan tanah. Semakin tinggi debit tetesan akanmenghasilkan luas areal pembasahan yang lebih besar. Begitu pula, dengan tekstur tanah, semakin kasar teksturnya maka luas pembasahan semakin kecil tetapi pembasahannya semakin dalam.

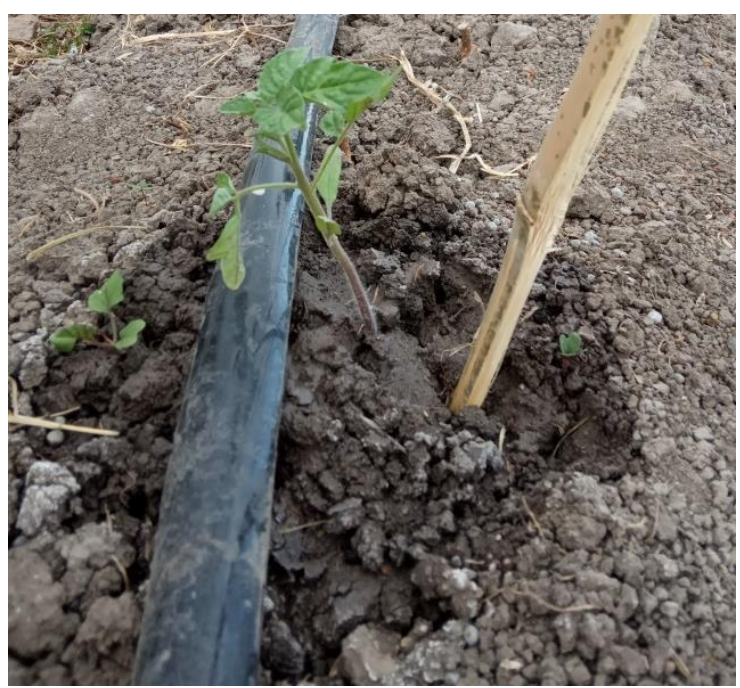

Gambar 5. Contoh pembasahan irigasi tetes

\section{Kebutuhan Air Tanaman}

Menurut (Purwanto and Ikhsan, 2013) bahwa faktor yang mempengaruhi kebutuhan air terdiri dari jenis tanaman, jenis tanah, cara pemberian air, pengolahan tanah, curah hujan, dan kondisi iklim. Berdasarkan hasil penelitian yang sudah dilakukan ini bahwa lokasi tempat percobaan tergolong curah hujan yang rendah dan merupakan lahan kering, sehingga untuk mengoptimalkan budidaya sepanjang tahun perlu diterapkan teknologi pemberian air yang efektif dan efisien.Teknologi yang dimaksud salah satunya dengan teknik irigasi tetes.Pemberian air dengan teknik irigasi tetes dapat diatur secara perlahan dan hanya membasahi areal perakaran.

Pada hasil penelitian dengan system penetes emitter, pemberian air dilakukan setiap 2 hari sekali selama 8 menit tiap pagi dan sore. Total penggunaan air pada pada masing-masing perlakuan dapat dilihat pada Tabel 3. Penggunaan air selama pertumbuhan vegetatif 
$10200 \mathrm{ml} /$ hari untuk perlakuan pada kemiringan $15^{\circ}$, $12200 \mathrm{ml} /$ hari untuk kemiringan $45^{\circ}$, dan pada perlakuan kemiringan $90^{\circ}$ menghabiskan air sebanyak $30800 \mathrm{ml} /$ hari. Berdasarkan hasil analisis statistik menunjukkan bahwa total penggunaan air pada perlakuan $15^{\circ}$ dan $45^{\circ}$ tidak berbeda nyata, tetapi kedua perlakuan ini berbeda nyata terhadap perlakuan $90^{\circ}$.
Sehingga dapat disimpulkan bahwa perlakuan terbaik pada debit kemiringan $15^{\circ}$ karena dengan kebutuhan air yang lebih sedikit dari perlakuan debit kemiringan keran $45^{\circ}$ dan $90^{\circ}$ sudah mampu mengoptimalkan pertumbuhan tanaman tomat.

Tabel 3

Total penggunaan air selama pertumbuhan vegetatif tanaman tomat

\begin{tabular}{|c|c|c|c|}
\hline Kemiringan Keran (o) & $\begin{array}{l}\text { Pertumbuhan } \\
\text { (minggu ke-) }\end{array}$ & $\begin{array}{l}\text { Volume Air } \\
\text { (ml/menit) }\end{array}$ & $\underset{\text { (ml/hari) }}{* \text { penggunaan air }}$ \\
\hline \multirow{3}{*}{15} & o & 11 & 2200 \\
\hline & 1 & 15 & 3000 \\
\hline & 2 & 12 & 2400 \\
\hline \multirow{2}{*}{ Total } & 3 & 13 & $\begin{array}{c}2600 \\
10200\end{array}$ \\
\hline & o & 16 & 3200 \\
\hline \multirow{3}{*}{45} & 1 & 16 & 3200 \\
\hline & 2 & 14 & 2800 \\
\hline & 3 & 15 & $\begin{array}{c}3000 \\
12200\end{array}$ \\
\hline Total & o & 38 & 7600 \\
\hline \multirow{2}{*}{90} & 1 & 40 & 8000 \\
\hline & 2 & 39 & 7800 \\
\hline Total & 3 & 37 & $\begin{array}{c}7400 \\
\mathbf{3 0 8 0 0}\end{array}$ \\
\hline
\end{tabular}

\section{SIMPULAN DAN SARAN}

Berdasarkan hasil perancangan dan pengujian penerapan irigasi tetes, maka dapat ditarik kesimpulan sebagai berikut :

1. Persentase nilai koefisien keseragaman (CU) pada perlakuan debit kemiriangan $15^{\circ}, 45^{\circ}$, dan $90^{\circ}$ sangat baik untuk diterapkan pada lahan kering, namun perlu pengontrolan karena sering terjadi penutupan lubang emiter akibat air irigas yang tidak tersaring.

2. Berdasarkan debit dan keseragaman tetes diperoleh areal terbasahi dengan lebar pembasahan $25 \mathrm{~cm}$ dan kedalaman mencapai $35 \mathrm{~cm}$.

3. Pertumbuhan vegetatif tanaman tomat pada perlakuan $15^{\circ}$ membutuhkan air sebanyak 10200 $\mathrm{ml} /$ hari, $12200 \mathrm{ml} /$ hari pada perlakuan $45^{\circ}$, dan $30800 \mathrm{ml} /$ hari pada perlakuan $90^{\circ}$.

Pada penelitian berikutnya perlu dilakukan penelitian lanjutan terkait tekstrur tanah dan kadar lengas untuk mengetahui penggunaan rancangan pada tempat yang berbeda. Selain itu juga perancangan ini perlu diujikan pada penutup bedengan menggunakan jerami dan tanpa menggunakan penutup untuk melihat perbandingan efektifitas pertumbuhan tanaman tomat.

\section{UCAPAN TERIMA KASIH}

Penulis mengucapkan terimakasih kepada DRPM Ristek Dikti yang sudah memberikan kesempatan dan dana untuk melaksankan penelitiandan terimakasih

\section{DAFTAR RUJUKAN}

Amuddin, A. and Sumarsono, J. (2015) 'RANCANG BANGUN ALAT PENYIRAMAN TANAMAN DENGAN POMPA OTOMATIS SISTEM IRIGASI TETES PADA LAHAN KERING (Design Tools Watering Plants With Automatic Pump to Drips Irrigation System For Dry Land)', Jurnal Ilmiah Rekayasa Pertanian dan Biosistem. doi: 10.29303/jrpb.v3i1.8.

Djumali and S., M. (2014) 'Pengaruh Kelembaban Tanah Terhadap Karakter Agronomi, Hasil Rajangan Kering Dan Kadar Nikotin Tembakau', Berita Biologi 13(1) - April 2014.

Ekaputra, E. G. et al. (2017) 'Rancang Bangun Sistem Irigasi Tetes untuk Budidaya Cabai (Capsicum Annum L.) dalam Greenhouse di Nagari Biaro, Kecamatan Ampek Angkek, Kabupaten Agam, Sumatera Barat', Jurnal Irigasi. doi: 10.31028/ji.v11.i2.103-112.

Fajar, A., Abdullah, S. H. and Priyati, A. (2018) 'Rancang bangun dan uji kinerja sistem kontrol fertigasi dengan irigasi tetes', 5(1), pp. 19-29.

Franata, R., Oktafri and Tusi, A. (2014) 'Rancang Bangun Sistem Irigasi Tetes Otomatis Berbasis Perubahan Kadar Air Tanah Dengan Menggunakan Mikrokontroler Arduino Nano', Jurnal Teknik Pertanian Lampung.

Haridjaja, O. et al. (2013) 'PERBEDAAN NILAI KADAR AIR KAPASITAS LAPANG BERDASARKAN METODE ALHRICKS , DRAINASE BEBAS , DAN PRESSURE PLATE PADA BERBAGAI TEKSTUR TANAH DAN HUBUNGANNYA DENGAN PERTUMBUHAN BUNGA MATAHARI ( Helianthus annuus L .) Different Levels of 
Field Capacity by Alhri', 15(2), pp. 52-59.

Indarta, A. H. and Tuasikal, H. (2020) 'RANCANG

BANGUN DAN EVALUASI KINERJA IRIGASI MIKRO

DI PULAU HARUKU , MALUKU DESIGN AND

PERFORMANCE EVALUATION OF MICRO-

IRRIGATION IN HARUKU ISLAND , MALUKU', 15(1),

pp. 31-44.

Mulyani, A. and Las, I. (2008) 'Potensi Sumber daya Lahan dan Optimalisasi Pengembangan Komoditas Penghasil Bioenergi di Indonesia', Jurnal Litbang Pertanian.

Phocaides, A. (2007) 'CHAPTER 7: Water quality for irrigation', Handbook of Pressurized Irrigation Techniques.

Purwanto and Ikhsan, J. (2013) 'Analisis Kebutuhan Air Irigasi pada Daerah Irigasi Bendung Mrican1', Jurnal Ilmiah Semesta Teknika.

Ridwan, D. (2013) 'MODEL OF DRIP IRRIGATION NETWORK WITH LOCAL MATERIAL BASED FOR AGRICULTURAL SMALL LAND Oleh':, 8(2), pp. 9098.

Rizal, M. (2013) 'RANCANG BANGUN DAN UJI KINERJA SISTEM KONTROL IRIGASI TETES PADA TANAMAN STRAWBERRY (Fragaria Vesca L)', Jurnal AgriTechno.

Sarwani, M. (2013) 'Karakteristik dan Potensi Lahan Sub Optimal untuk Pengembangan Pertanian di Indonesia'.

Selvamurugan, M. et al. (2018) 'Effect of drip fertigation and plastic mulching on growth and yield of tomato', Journal of Applied Horticulture. doi: 10.37855/jah.2018.v20io1.14. 